\title{
Multi objective design of high efficiency induction motor using an analytical method's
}

\author{
O. Zeghba, S. Chakroune*, S. Belhamedi
}

Research Laboratory on Electrical Engineering, Faculty of Technology, M'Sila University, 28000 Algeria

Corresponding Author Email: chakroune.chakroune@yahoo.com

https://doi.org/10.18280/mmc_a.910406

Received: 10 July 2018

Accepted: 15 October 2018

\section{Keywords:}

constraints design, induction motor, efficiency evaluation, analytical method

\begin{abstract}
In the final decade of the last century, there was enormous intellectual and engineering activity surrounding the recently invented induction motor, especially their efficiency increasing. The interest in improving the efficiency of electric motors stems from the fact that they represent 60 to $70 \%$ of the total industrial and commercial load. A knowledge the motors operating efficiency in an industrial plant is necessary, when deciding whether standard motors should be advantageously replaced with more efficient motors. A new approach is presented for analysis and design of closed rotor slot induction motors in this paper. The main idea is illustrated as follows: first based the computed machine parameters and motor geometry optimization will be carried out. Then, to validate the conceived machines, dynamical performance analysis will be achieved by MATLAB environment. Finally using finite element electromagnetic field analysis, the comparison results will be discussed and commented.
\end{abstract}

\section{INTRODUCTION}

In regard to the high performance and features of induction machines, such as simplicity, ruggedness, reliability, they have been widely used in much application. Their exploitation in many cases looks towards a best possible of their behavior, [1].

As a consequence, with the continuing increase of the cost energy and the pressure caused by the worry environmental protection. Electrical machines manufactures as well as interested in the energy reduction consumption, which is translated by a global warmness to intensify the energy saving research worldwide, [1-3]. For these reasons, electric energy consumers are interested to use apparatus driven by electrical machines with high efficiencies in order to reduce their cost. In the last decades, new generation of motors have been emerged on the world market and known as High Efficiency Motors (H.E.M). These new types of motors are relatively more expensive than the conventional ones, in the range of 20$40 \%$, from larger to lower power range respectively [3].

The electric driven system efficiency depends on several factors such as: motor efficiency and control techniques, power system and distribution network qualities, system over sizing, mechanical transmission means, maintenance problems and practices, load management and operating cycles. To improve electric driven system efficiencies, different approaches are proposed. They mainly use variable speed drives, regulate and stabilise the electric power network, choose an optimal power size of the electric motors or improve their designs and efficiencies. The three first approaches are related to electric power network system, but the last ones are related to the motor design itself [2].

Kept in perspective by taking into consideration the energy saving potential during the motor design stage, as well as its operation. The previous efforts were always made to save energy in motor application by using energy only as much as what was needed during operating. The best way is to exploit the saving potential during motor design. However taking into consideration, its intended application, it can be achieved either through the improvement of motor design or through the reduction of the electrical input energy when the motor has been already existed, As well as, first we have to act by an appropriate choice of the motor sizing, or by operating the motor in an efficient way, so using external intervention [4]. Second, by acting on the motor design, which means increasing the volume of the active material (Iron and Copper), using longer machines in order to keep the same slot design, selecting lower current density and a higher copper slot fill-factor, choosing new material with high magnetic performances (low iron losses), and optimizing the motor design according to its efficiency.

The objective of this paper is to clearly discuss those factors In the first part, we recall all the advantages of high efficiency motors and expected performance. The different approaches and LIWSHITZ steps method will be applied on an asynchronous motor's of $5 \mathrm{~kW}$ is the subject of the second part. The different characteristics of this machine will be deduced using a program under MATLAB.

Finally, the finite element method will be used to obtain the different characteristics of our machines for different operating conditions. We will conclude with a summary of the results found for the $\Delta$ coupling.

\section{EFFICIENCY STANDARDS AND WORLD CHALLENGE}

The International IEC 60034-30-1 2014 Standard, assures a regular international basis design and electric motors classification as well as national governmental activities. Thus raising the harmonization level performance standards MEPS (Minimum Energy Performance Standard). The standard defines the international efficiency classes (IE code) and 
requirements corresponding, provides the test conditions and performance measurement methods described in IEC 600342-1 2007, but does not establish motors minimum performance level (MEPS); this depends on the different legislation force countries and governmental objectives about energy saving and ecological sustainability [4-5].

\subsection{Europeans}

The regulation 640/2009 Article 3 implemented eco-design directive 2005/32 / EC and imposes a strict standards performance on electric motors, labeled IE1 (Standard Efficiency), IE2 (High Efficiency) and IE3 (Premium Efficiency). In June 2011 the motor efficiency will have to reach the IE2 label, and the IE3 label (or IE2 with a variable speed drive) in January 2017. European Commission means at 2020 to reduce electricity consumption by $135 \mathrm{TWh}$ [4].

\subsection{United States USA}

Energy Independence and Security Act (EISA) was signed in December 2007 and deposit into effect in 2010 (last updated in 2014). The EISA standard replaces EPAC Energy Policy Act approved by the US Congress in 1992 and establishes the IE3 Super Premium NEMA performance standard as a minimum level for AC three-phase industrial motors for general use 1 to $500 \mathrm{HP}$ manufactured or imported for transaction in the United States. The United States Department Energy (DOE) is responsible for defining regulations to apply $[5,6]$.

\subsection{Canada}

Canada has implemented minimum energy performance standards since 1995, these standards were amended in 1997 revised since June 2016. The minimum efficiency levels considered are IE3 and the nameplate indicates the efficiency at $100 \%$ NEMA nominal load and certificate symbols such as CSA [7].

\subsection{Australia}

Australian MEPS standards be announced in 2001 by the Australian Green House Office (AGO), and were reviewed in 2006. All systems covered by these standards, sold in Australian markets and New Zealand will need to be registered in a national online database system. The AS/NZS 1359.5/2004 standards include two levels performance: The minimum efficiency level performance IE2 and a high level performance IE3 or upper. The standards are controlled by an official organization that performs random testing to prove conformity and the importation motor is subject to severe penalties $[2,7]$.

\subsection{Germany}

The German Standards Institute is a private organization with the status non-profit association. Its members come from industry association's public authority's trade, professional organizations and research organization by agreement with the German Federal Government. DIN is the approved national standardization body representing German interests in international and European standardization organizations [1, $8]$.

\section{HIGH EFFICIENCY MOTORS}

Replacing an existing motor with a high efficiency motor reducing the total electrical energy consumed $(\mathrm{kWh})$. It can also improve the power factor in some cases.

The success replacing an existing motor analysis with a high-efficiency motor makes it possible to check the actual required demand for this equipment, which is frequently too high. Really the majority industries use oversized motors to protect, against motor failures give opportunity to increase production and make load fluctuations [1-2]

\subsection{Efficiency improved}

We have numerous parameters to improve an induction motor efficiency:

1) Bearings design optimization to reduce friction losses;

2) Increase copper and coils sections permit diminish joule stator losses;

3) Short-circuit rings and bars materials quality as well as sections to decrease rotor losses;

4) An efficient ventilator reduces the losses due to ventilation effect;

5) Increased airflow reduces mechanical losses;

6) High quality magnetic sheets used to reduce iron losses especially Hysteresis cycle effect.

7) A excellent slots dimensioning and coil larger diameter makes it possible to reduce the magnetic losses;

8) A large length stator reduces the magnetic field densities also improving the cooling capacity motor, in addition reducing the magnetic losses under load [9].

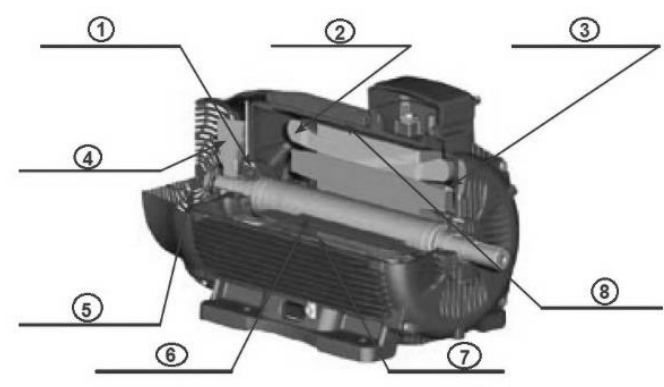

Figure 1. Increase motor efficiency zones action

\subsection{Design methods}

In order to design electrical machines, there are numerous methods it is a principally large field whose approach uses a lot of assumptions. Throughout our research we found ourselves in front at several kinds' methods specific to every designers, in general the method does not change since we always notice the same path that allows stator sizing followed a rotor calculation. Static and dynamic characteristics are calculated from the machine equivalent circuit, [10]. Afterward we propose four calculation methods encountered in our study:

\subsubsection{First method}

This method proposed by Marcel Jufer and Jean-Claude Sabonnadière, is based on the calculation using initially the formulas iron stator dimensioning then they establish rotor calculation. The magnetic circuit sizing is based on the following constraints: 
- An induction level resultant to the saturation has imposed so as to limit iron losses while decreasing the iron mass volume, then define this induction level via geometry and magnetic flux conservation rule;

- The bore diameter and active length are the typical sizing process dimensions.

But the associated key factor is a radial air gap induction, its sinusoidal distribution [10].

\subsubsection{Second method}

This second teaching method used at the MONTREAL Polytechnic School is a didactic method. The suggested method offers certain flexibility to parameters definite. A compromise must be made such as the bore diameter motor for example and the result obtained must sometimes be changed to meet the requirements. This method also includes the rotor slots oblique array dispersions [10].

\subsubsection{Third method}

This procedure, combines computation and induction machine computer-aided design, and borrows different calculation phase's chronological order. This approach is based on the design principle of G.Kouskoff and Liwschitz. Except that we impose the geometric data of an already existing industrial machine, as constraints to which we must offer. The numerical calculation results are compared with those given by the classical test method then processed by analysis simulated dynamic machine behavior in order to develop the correlation and concordance of these design results with those delivered by the manufacturer of the induction motor studied [3].

\subsubsection{Proposed method}

This design procedure of electrical machine it is based on Liwschitz method (L.M) where can be summarized in three main stages:

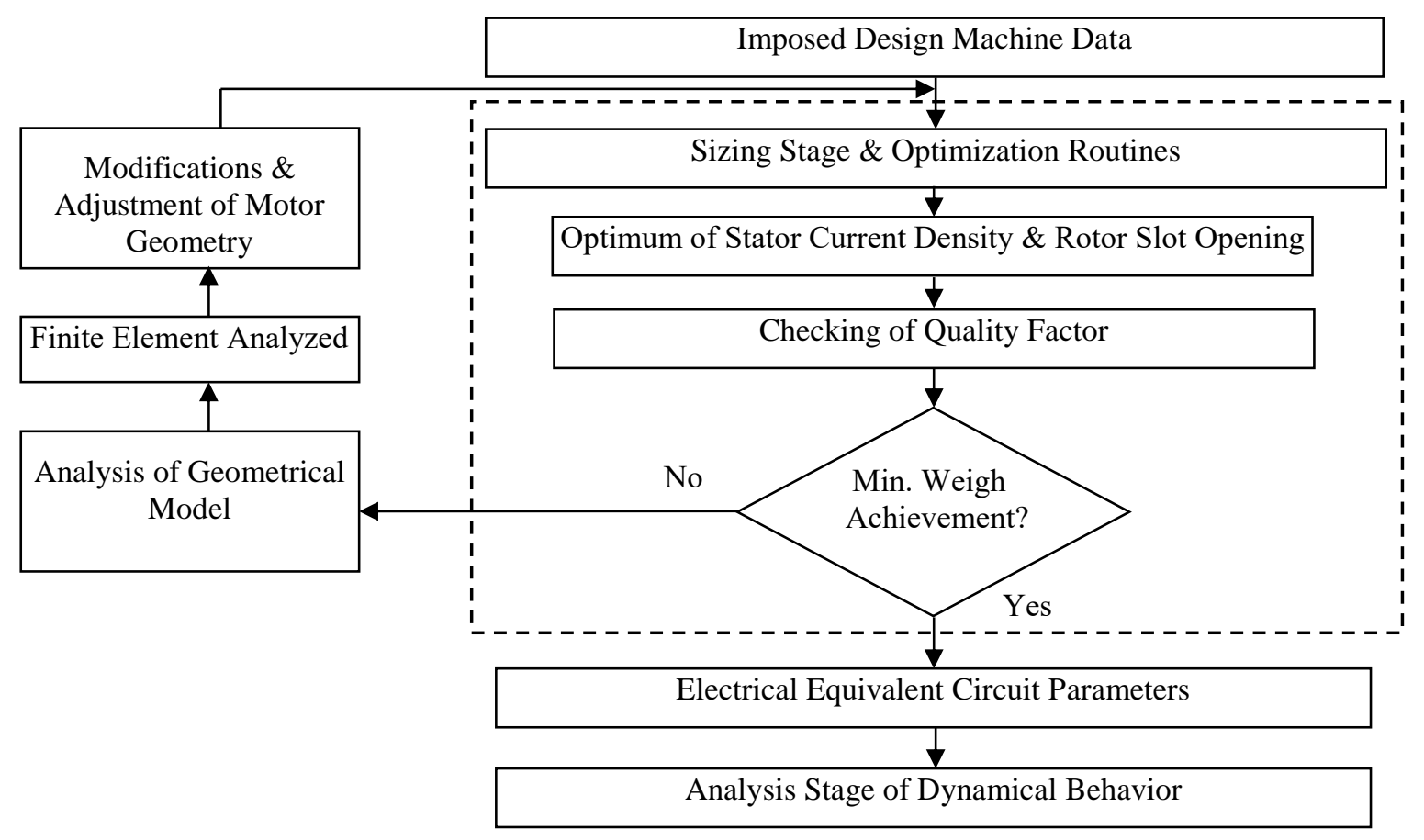

Figure 2. Global proposed machine design procedure

1) From the imposed machine design data and the output equations $(C)$, finding the optimized machine dimensions, which are characterized by the active volume $\left(\mathrm{D}^{2} 1_{i}\right)$ given by the stator diameter and the stack length of the machine, leading to the parameter of the electrical equivalent circuit of the machine.

$$
\frac{\mathrm{S}_{\mathrm{i}} \cdot 10^{-3}}{\mathrm{D}^{2} 1_{\mathrm{i}} 60 \mathrm{n}_{\mathrm{S}}}=\frac{\mathrm{K}_{\mathrm{w} 1} \mathrm{~B}_{\delta} \mathrm{A}_{1}}{8.6 \cdot 10^{3}}=\mathrm{C}
$$

where:

$\left(S_{i}\right)$ is the apparent power calculates according to a set of experimental curves the normalized values of the power factor $(\cos \phi)$ and efficiency $(\eta)$, and $\left(A_{1}, B_{\delta}\right)$ is respectively the linear charge in addition to air gap flux density. Lastly $\left(K_{w 1}\right)$ is the total stator winding coefficient on the other hand $\left(n_{s}\right)$ is synchronization speed, [11, 12].

From which we can deduce primary phase number turns:

$$
\mathrm{N}_{1}=\frac{\mathrm{V}_{1}\left(\frac{1}{1+\sigma_{\mathrm{H} 1}}\right)}{4 \cdot \mathrm{k}_{\mathrm{f}} \cdot \mathrm{f}_{1} \cdot \mathrm{K}_{\mathrm{w} 1} \phi}
$$

$\frac{1}{1+\sigma_{H 1}}$ Primary dispersion coefficient obtained from a diagram;

$f_{1}$ Supply frequency.

\section{- Magnetic Sizing}

Knowing the dimensions value we calculate the flux per pole. We can easily determine flux density values and the magnetic field in each section.

$B_{i}=\frac{\varphi_{i}}{S_{i}}, H_{i}=\frac{B_{i}}{\mu_{i}}, \mu_{i}=\mu_{0} \mu_{r i}$

In favor of taken into account the presence opening slot to 
calculate the virtual pole pitch; the latter is taken into account by replacing the air gap $\delta$ by a fictitious air gap $\delta^{\prime}$ : such as $\frac{\delta^{\prime}}{\delta}=K_{c}>1$ is called Carter factor.

$$
\left\{\begin{array}{l}
\mathrm{K}_{\mathrm{c}}=\frac{\tau_{\mathrm{Z}}}{\tau_{\mathrm{Z}}-\gamma_{\mathrm{B}} \cdot \delta} \\
\gamma_{\mathrm{B}}=\frac{4}{\pi}\left(\frac{\mathrm{Ws}}{2 \delta} \operatorname{artg} \frac{\mathrm{s}}{2 \delta}-\ln \sqrt{1-\left(\frac{\mathrm{Ws}}{\delta}\right)^{2}}\right)
\end{array}\right.
$$

Where $(W s)$ is the slot opening and $\tau_{Z}$ the tooth pitch.

When the two parts of the machine (stator and rotor) are notched, we calculate:

$K_{c 1}$ For a smooth stator;

$K_{c 2}$ For a smooth rotor.

$K_{c}=K_{C 1} \cdot K_{C 2}$ Where $K_{c}$ is the total Carter factor.

From where the air gap magneto motive force is:

$\mathrm{F}_{\delta}=\frac{\mathrm{B}_{\delta}}{\mu_{0}} \cdot \mathrm{K}_{\mathrm{c}} \cdot \delta=\frac{\phi_{\delta}}{\mathrm{S}_{\delta} \cdot \mu_{0}} \cdot \mathrm{K}_{\mathrm{c}} \cdot \delta$

\section{- $\quad$ Teeth Magneto motive}

In practice, however we use the Simpson rule which gives good results. Knowing that the tooth is divided into three parts, the average field intensity is calculated as follows:

$$
\mathrm{H}_{\text {z.moy }}=\frac{1}{6}\left(\mathrm{H}_{\text {z. min }}+4 \cdot \mathrm{H}_{\text {z.med }}+\mathrm{H}_{\text {z. max }}\right)
$$

The magnetic potential tooth value is:

$$
\mathrm{F}_{\mathrm{z}}=\mathrm{h}_{\mathrm{z}} \cdot \mathrm{H}_{\mathrm{z} \cdot \mathrm{moy}}
$$

This formula is applicable for rotor and stator. We redo the same calculations for both parties while considering the characteristics of each of them.

\section{- Magnetizing Current}

Equation (8) calculates the magnetizing current [4, 11].

$$
\mathrm{I}_{\mathrm{m} 0}=\frac{\mathrm{p} \cdot \mathrm{F}_{\text {tot }}}{0.9 \cdot \mathrm{m}_{1} \mathrm{~N}_{1} \mathrm{~K}_{\mathrm{w} 1}}
$$

\section{- Bar Current and Shorting Ring}

$$
\begin{aligned}
& I_{2}=\frac{P_{u}+P_{(f t+v t)}+P_{\text {sup }}}{m_{2} \cdot E_{2}(1-g)} \\
& I_{\text {an }}=\frac{I_{2}}{2 \sin \frac{\pi P}{Z_{2}}}
\end{aligned}
$$

$m_{2}=Z_{2}$ Secondary phase number; $P_{u}$ Nominal power; $P_{(f t+v t)} \quad$ Mechanical losses;
$P_{\text {sup }}$ Additional losses;

2) The results of stage 1, evaluating the machine performances qualities, in order to check whether or not the design machine operates as the desired specification.

\section{-Calculation of Stator Resistance}

The stator resistance $\left(R_{s}\right)$ are expressed by:

$$
\mathrm{R}_{\mathrm{s}}=\rho \cdot \frac{\mathrm{L}_{\mathrm{tot}}}{\mathrm{S}}
$$

where: $S$ Conductor cross section area; $L_{t o t}$ Total conductor length per phase.

\section{-Calculation of the Leakage Reactance}

\section{- Total Stator Leakage Reactance}

The stator leakage inductance is deduced from the total stator leakage reactance as follows:

$$
1_{\sigma \mathrm{s}}=\frac{\mathrm{X}_{\sigma 1}}{\omega}=4 \cdot \pi \cdot \mathrm{f}_{1} \frac{\mathrm{N}_{1}^{2}}{\omega \cdot \mathrm{p}} \cdot\left(\Lambda_{\sigma \mathrm{b} 1}+\Lambda_{\sigma \mathrm{z} 1}+\Lambda_{\sigma \mathrm{d} 1}\right)(12)
$$

\section{- Total Rotor Leakage Reactance}

The rotor leakage inductance is expressed as follows.

$1_{\sigma \mathrm{r}}=\frac{\mathrm{X}_{\sigma 2}}{\omega}=4 \cdot \pi \cdot \frac{\mathrm{f}_{1}}{\omega 2 \mathrm{p}} \cdot\left(\Lambda_{\sigma \mathrm{b} 2}+\Lambda_{\sigma \mathrm{z} 2}+\Lambda_{\sigma \mathrm{d} 2}\right)$

where:

$\Lambda_{\sigma b 1}, \Lambda_{\sigma b 2}$ End coil permeances of stator and rotor; $\Lambda_{\sigma d 1}, \Lambda_{\sigma d 2}$ Differential permeances of stator and rotor; $\Lambda_{\sigma z 1}, \Lambda_{\sigma z 2}$ Permeances of stator and rotor slot.

\section{-Assessment of the Losses}

\section{- Copper losses}

In the Stator: The copper losses in the stator coils $\left(P_{c u 1}\right)$ are given by:

$\mathrm{P}_{\mathrm{cu} 1}=\mathrm{m}_{1} \cdot \mathrm{R}_{\mathrm{s}} \cdot \mathrm{I}_{\mathrm{s}}^{2}$

In the Rotor: The copper losses in the secondary $\left(P_{c u 2}\right)$ are:

$\mathrm{P}_{\mathrm{cu} 2}=\mathrm{m}_{2} \cdot \mathrm{R}_{2} \cdot \mathrm{I}_{2}^{2}$

$\mathrm{R}_{2}=\mathrm{R}_{\mathrm{bar}}+\frac{2 \cdot \mathrm{R}_{\mathrm{ring}}}{4 \cdot \sin ^{2} \frac{\pi \cdot \mathrm{p}}{\mathrm{Z}_{2}}}$

The equivalent phase resistance $R_{r}^{\prime}$ refereed to the stator side is:

$\mathrm{R}_{\mathrm{r}}^{\prime}=\left(\frac{\mathrm{m}_{1}}{\mathrm{~m}_{2}}\right) \cdot\left(\frac{\mathrm{N}_{1}}{\mathrm{~N}_{2}} \cdot \frac{\mathrm{K}_{\mathrm{W} 1}}{\mathrm{~K}_{\mathrm{W} 2}}\right)^{2} \cdot \mathrm{R}_{2}$

where

$R_{\text {bar }}, R_{\text {ring }}$ Bar and ring resistances; 
$R_{2}, \quad Z_{2}$ Rotor resistance and bar number;

$N_{1}, N_{2}$ Stator and rotor turns by phase;

$K_{W 2}$ Total rotor winding coefficient;

$m_{1}, m_{2}$ Stator and rotor phase number.

\section{- Iron losses}

The sum of the losses $\left(p_{H+W}\right)$ in one iron $\mathrm{kg}$ is given by:

$\mathrm{p}_{\mathrm{H}+\mathrm{W}}=\mathrm{K}_{\mathrm{H}} \cdot \mathrm{f} \cdot \mathrm{B}^{2} \cdot 10^{-2}+\mathrm{K}_{\mathrm{W}} \cdot\left(\mathrm{S}_{\mathrm{t}} \cdot \mathrm{f}_{1} \cdot \hat{\mathrm{B}}\right)^{2} \cdot 10^{2}$

The constants $K_{H}, K_{W}$ for the different materials are given by normalized rang.

Where:

$\widehat{B}$ Peak air gap flux dens;

$S_{t}$ Metal sheet thickness

- Mechanical losses

These losses are taken into account with rubbings due to the rotation of the mobile part of the machine, and they are estimated according to the speed $[8,11]$.

-Determination of No-Load Parameters

The stator no-load current $\left(I_{o}\right)$ comprises the magnetizing current $\left(I_{m_{o}}\right)$ and load losses one $\left(I_{o a}\right)$.

$$
\begin{aligned}
& \mathrm{I}_{\mathrm{o}}=\mathrm{I}_{\mathrm{mo}}+\mathrm{I}_{\mathrm{oa}} \\
& \mathrm{I}_{0 \mathrm{a}}=\frac{\mathrm{P}_{\mathrm{sup}}+\mathrm{P}_{\mathrm{ft}+\mathrm{vt}}}{\mathrm{m}_{1} \cdot \mathrm{V}_{\mathrm{s}}} \\
& \cos \varphi_{\mathrm{o}}=\frac{\mathrm{I}_{\mathrm{ao}}}{\mathrm{I}_{\mathrm{o}}}
\end{aligned}
$$

The no-load reactive power $\left(Q_{0}\right)$ is:

$$
\mathrm{Q}_{\mathrm{o}}=3 \cdot \mathrm{V}_{\mathrm{s}} \cdot \mathrm{I}_{0} \cdot \sin \varphi_{0}
$$

where:

$P_{f t+v t}$ Rubbing and ventilation losses;

$\phi_{0}$ Phase angle at no-load;

$F_{m m t o t}$ Total magneto motive force calculated according Simpson method;

$P_{\text {sup }}$ Supplementary losses;

Therefore, the total stator inductance $\left(L_{s}\right)$ is determined as follows:

$\mathrm{L}_{\mathrm{s}}=\frac{\mathrm{Q}_{0}}{3 \cdot \omega_{\mathrm{s}} \cdot \mathrm{I}_{0}^{2}}=\frac{3 \cdot \mathrm{V}_{\mathrm{s}} \cdot \mathrm{I}_{0} \cdot \sin \varphi_{0}}{3 \cdot \omega_{\mathrm{s}} \cdot \mathrm{I}_{0}^{2}}$

After having determined $\left(L_{S}\right)$ and $\left(l_{\sigma S}\right)$, the mutual inductance is expressed by:

$\mathrm{M}=\mathrm{L}_{\mathrm{s}}-1_{\sigma \mathrm{s}}$

And the total rotor inductance referred to the stator side $\left(L_{r}^{\prime}\right)$ is determined:

$$
\mathrm{L}_{\mathrm{r}}^{\prime}=\mathrm{M}+\mathrm{l}_{\sigma \mathrm{r}}^{\prime}
$$

Finally the efficiency is:

$\eta=\frac{P_{m}}{P_{m}+\sum \text { Losses }}$

3) The last stage consist a series of alternative design for the specified power, voltage, and speed were examined to give the best starting guesses for an optimum of power density $[4,8]$.

\subsection{Machine description}

To explore and to evaluate the design procedure, two $5-\mathrm{kW}$ type DIN-IEC-F induction motors have been designed, considering some constraints in terms of voltage regulation, number of poles, speed rang, and cheapest manufacturing techniques. The first one is a single Carter coefficient (M1), and the second one is a double coefficient (M2) as well as with profound stator slots its data specifications are given in Table 1 .

Table 1. Machine data

\begin{tabular}{|c|l|l|l|}
\hline$P_{m}$ & Output mechanical power & 5 & $\mathrm{~kW}$ \\
\hline$V S$ & Stator voltage & 380 & $\mathrm{~V}$ \\
\hline$p$ & Number of pole pairs & 2 & --- \\
\hline$m_{1}$ & Numbers of stator phases & 3 & --- \\
\hline$f_{s}$ & Supply frequency & 50 & $\mathrm{~Hz}$ \\
\hline$n_{r}$ & Rotor speed & 1440 & $\mathrm{tr} / \mathrm{min}$ \\
\hline$\Delta$ & Coupling mode & \multicolumn{2}{|l}{} \\
\hline
\end{tabular}

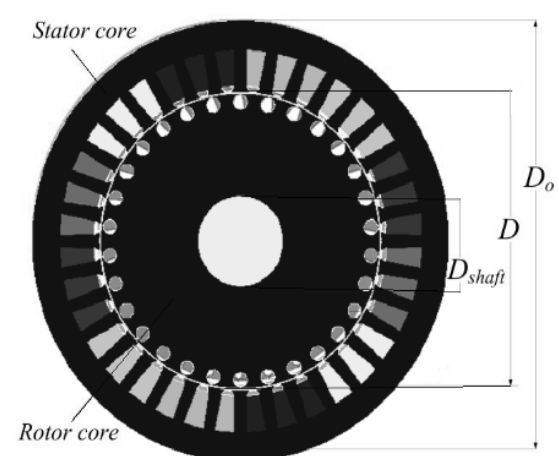

(a) Main dimensions

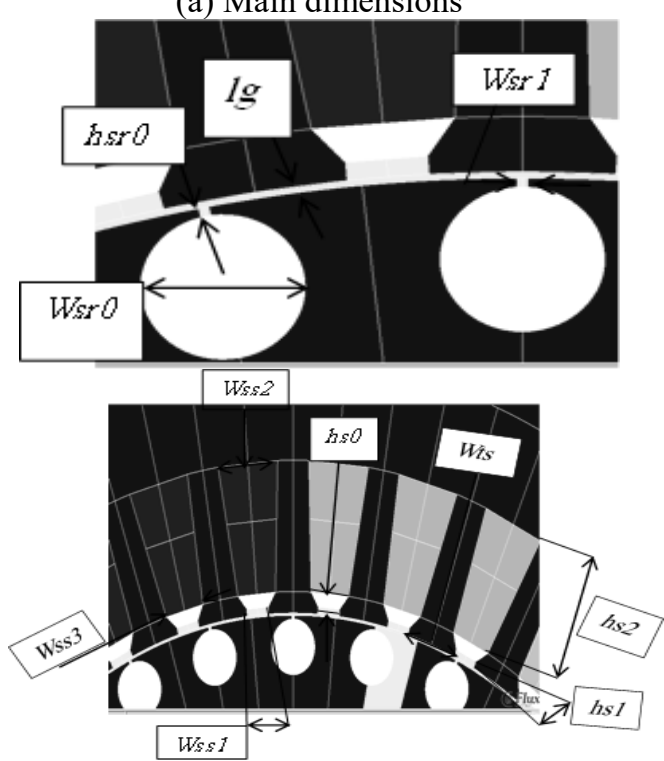

(b) Detailed rotor and stator slot

Figure 3. A typical machine's 
Figure 3(a) shows a general overview of the machine's main dimensions, while Figure 3(b) shows the detailed rotor and stator geometries.

Due to the large number of parameters, their names and meaning will be stated in the next table.

\subsubsection{Design Results}

The numerical results, are obtained from the design program developed in our group for classic induction machine design under MATLAB environment, which has been modified for the closed rotor slot topology. Table 2 summarizes and compresses the computed design parameters of these two motor prototypes.

Table 2. Computed design parameters of three- phase machines under study

\begin{tabular}{|c|c|c|c|c|c|c|c|c|}
\hline \multirow[b]{2}{*}{ Quantity } & \multicolumn{4}{|c|}{ M1 } & \multicolumn{4}{|c|}{ M2 } \\
\hline & Stator & $\begin{array}{l}\text { Value } \\
{[\mathrm{mm}]}\end{array}$ & Rotor & $\begin{array}{l}\text { Value } \\
{[\mathrm{mm}]}\end{array}$ & Stator & $\begin{array}{l}\text { Value } \\
\text { [mm] }\end{array}$ & Rotor & $\begin{array}{l}\text { Value } \\
{[\mathrm{mm}]}\end{array}$ \\
\hline Slot width at teeth & WsS1 & 4 & Wsrl & 0.5 & Wss 1 & 4 & Wsrl & 3 \\
\hline Slot width at opening & Wss2 & 7 & & 1 & Wss2 & 7 & & 1 \\
\hline Slot width at end & Wss 3 & 11.1 & WsrO & 8 & Wss 3 & 11.8 & Wsr0 & 8 \\
\hline Teeth width & $W t s$ & 9 & & 1 & $W t s$ & 9 & & 1 \\
\hline Slot height at teeth & hso & 2 & hsro & 0.5 & hso & 2 & hsro & 0.5 \\
\hline Slot height at opening & $h s 2$ & 18.7 & $\lg$ & 0.35 & $h s 2$ & 23 & & \\
\hline Air gap diameter & $D$ & 150 & Dshaft & 45 & $D$ & 150 & Dshaft & 45 \\
\hline Outer diameter & Do & 250 & $D r$ & 149.3 & Do & 259 & $D r$ & 149.3 \\
\hline Machine weight & MW & $\mathrm{kG}$ & \multicolumn{2}{|c|}{49.34} & \multicolumn{4}{|c|}{53.09} \\
\hline Power factor & $\cos \phi$ & l & \multicolumn{2}{|c|}{0.855} & \multicolumn{4}{|c|}{0.848} \\
\hline Stator current at no-load & $I_{o}$ & $A$ & \multicolumn{2}{|c|}{1.976} & \multicolumn{4}{|c|}{2.197} \\
\hline Starting current & $I_{C C}$ & $A$ & \multicolumn{2}{|c|}{36.09} & \multicolumn{4}{|c|}{38.432} \\
\hline Magnetizing Current & $I_{m}$ & $A$ & \multicolumn{2}{|c|}{1.964} & \multicolumn{4}{|c|}{2.186} \\
\hline Rubbing and ventilation losses & $P_{f t+v t}$ & $\mathrm{~W}$ & \multicolumn{2}{|c|}{80} & \multicolumn{4}{|c|}{80} \\
\hline Total Iron losses & $\left(p_{H+W}\right)$ & $\mathrm{W}$ & \multicolumn{2}{|c|}{193.17} & \multicolumn{4}{|c|}{206.25} \\
\hline Air-gap length & $\delta$ & $\mathrm{mm}$ & \multicolumn{2}{|c|}{0.447} & \multicolumn{4}{|c|}{0.505} \\
\hline Efficiency & $\eta$ & ----- & \multicolumn{2}{|c|}{0.8644} & \multicolumn{4}{|c|}{0.8644} \\
\hline Mutual inductance & $M$ & $H$ & \multicolumn{2}{|c|}{0.5991} & \multicolumn{4}{|c|}{0.5369} \\
\hline Rotor resistance referred to the stator side & $R_{r}^{\prime}$ & $\Omega$ & \multicolumn{2}{|c|}{3.0428} & \multicolumn{4}{|c|}{3.0428} \\
\hline Stator resistance & $R_{S}$ & $\Omega$ & \multicolumn{2}{|c|}{2.4027} & \multicolumn{4}{|c|}{1.8020} \\
\hline stator leakage inductance & $l_{\sigma s}$ & $H$ & \multicolumn{2}{|c|}{0.0167} & \multicolumn{4}{|c|}{0.0164} \\
\hline $\begin{array}{l}\text { Rotor leakage reactance referred to the } \\
\text { stator side }\end{array}$ & $l_{\sigma r}^{\prime}$ & $H$ & \multicolumn{2}{|c|}{0.0115} & & & & \\
\hline Stator back iron flux density & $B_{h j 1}$ & $T$ & & 2 & & & & \\
\hline Tooth flux dens in stator & $B_{t 1}$ & $T$ & & 39 & & & & \\
\hline Peak Air-gap flux density & $B_{\delta}$ & $T$ & & & & & & \\
\hline Stator slot / Rotor bar number & & & & & & & & \\
\hline $\mathrm{T}_{\mathrm{star}} / \mathrm{T}_{\mathrm{n}}$ & -------- & --------- & & & & & & \\
\hline
\end{tabular}

Through the design program results, there is an increase in the magnetizing current for M2. This raise is due mainly to the air gap and therefore to the f.m.m in the latter since they are proportional. On the other hand, an efficiency improvement is observed by the use of a deep slot stator side.

As a result of this investigation, the current circular diagram $[2,8]$. The H-G diagram (Figure 4) and three motor characteristics $\boldsymbol{I} \boldsymbol{s}=\boldsymbol{f}(\boldsymbol{S}), \boldsymbol{T} \boldsymbol{e}=\boldsymbol{f}(\boldsymbol{S})$ and efficiency $\boldsymbol{E t a}=$ $\boldsymbol{f}(\boldsymbol{S})$ are drawn as depicted in Figure 5, Figure 6 and Figure 7 respectively. These last figures are zoomed so as to highlight the performance of the proposed method in particular points range.

The analysis of the Figure 4, show that the plotted of particular points obtained by the circular diagram are confounded on the theoretical H-G diagram. So it can be concluded that the LIWSHITZ analytical models are in good correlation [2].

Figure 5 presents and compares an important characteristic for these two machines, which we observe that, the current starts from a low value it is the no load current, increases according to the slip before incoming at the starting current. We also note that the deep slot machine (M2) have a starting current greater than 2.46A compared to (M1) is very significant.

This adjust is accompanied by a maximum torque improvement and starting torque about $10 \mathrm{Nm}$ (Figure 6). As well as the machine efficiency $+0.5 \%$ hence multi objective design (Figure 7).

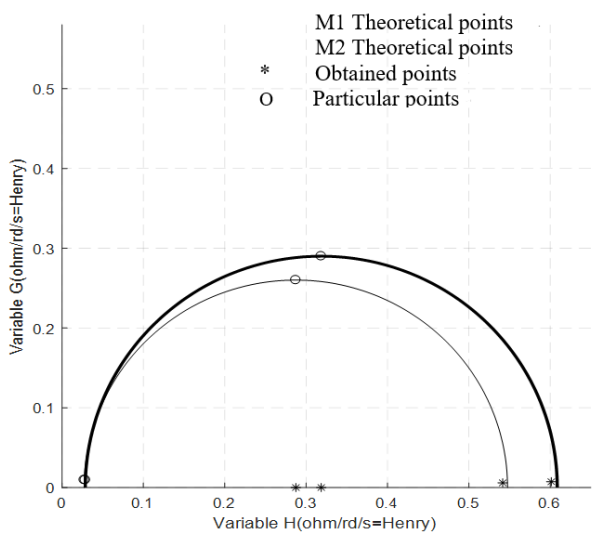

Figure 4. H-G Diagram with current circular diagram 


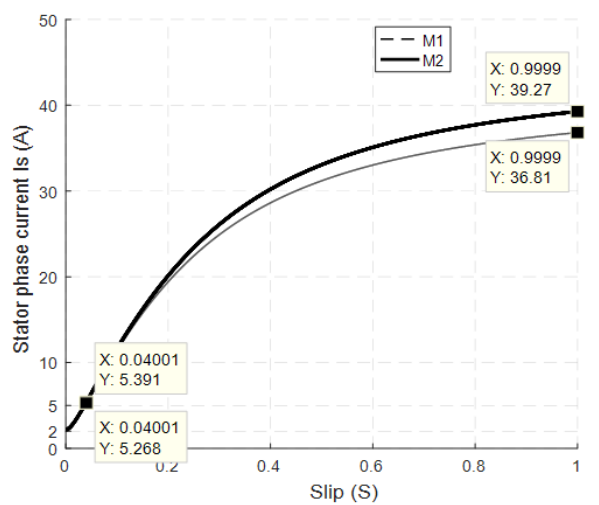

Figure 5. Stator phase current versus rotor slip

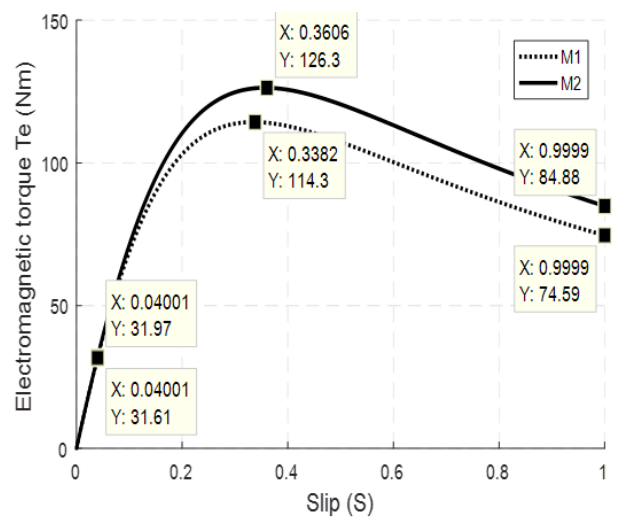

Figure 6. Electromagnetic torque versus rotor slip

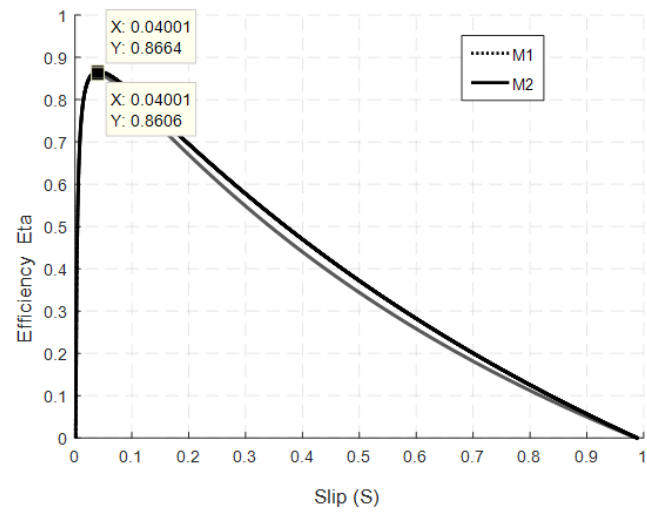

Figure 7. Efficiency versus rotor slip

\subsubsection{Open loop behavior analysis}

The evolution currents and speed study in dynamic mode by simulation, is a very effective means results validation. Indeed, the simulation, will study the influence of each parameter and calculate the quantities that are not directly accessible to the measurement (i.e. the rotor currents in).

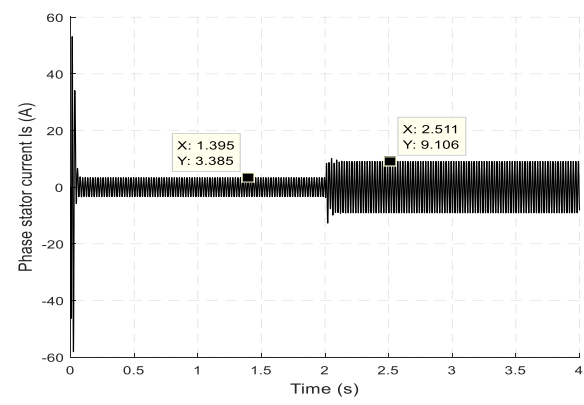

(a) Stator phase current versus time M1

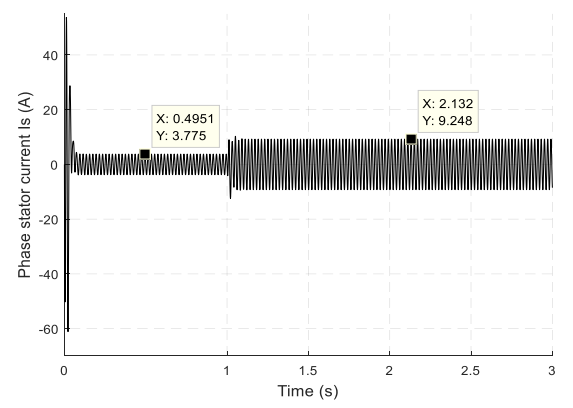

(b) Stator phase current versus time M2

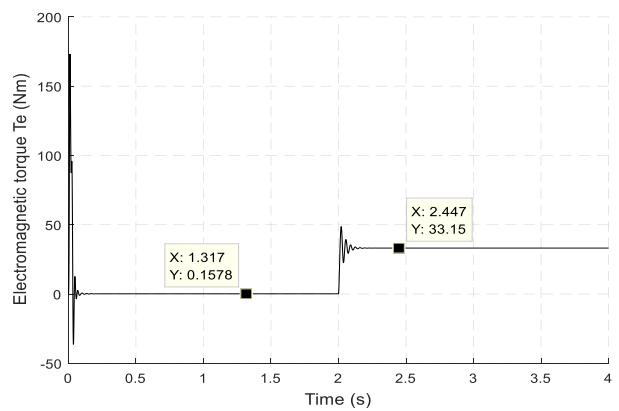

(c) Electromagnetic torque versus time M1

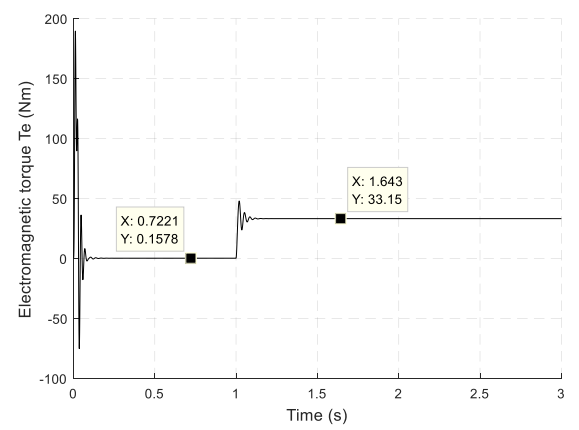

(d) Electromagnetic torque versus time M2

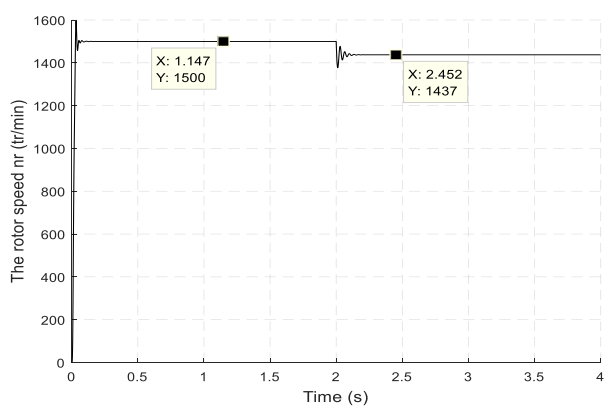

(e) Rotor speed versus time M1

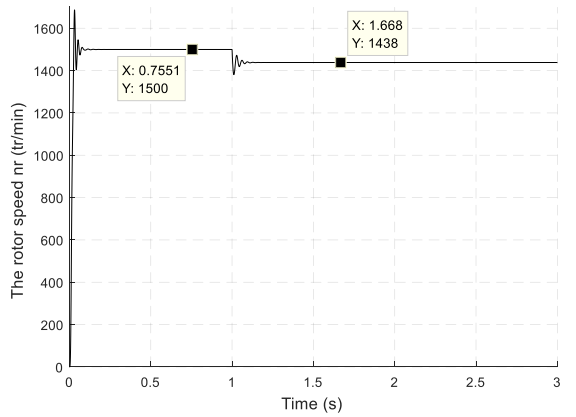

(f) Rotor speed versus time M2

Figure 8. Under nominal load characteristics

Using the results grouped in Table 2 and PSB blocks (Power System Block) of the MATLAB, we will verify the nominal 
torque (nominal load), starting torque and maximum torque test $[4,8]$.

As the second test, we will apply to machines gradually received a torque greater than the nominal torque in order to determined the starting torque.

Finally, a maximum torque is applied at time $(\mathrm{t}=1 \mathrm{~s})$ to determine the load capacity of these two machines. This is illustrated by the speed and torque curve.

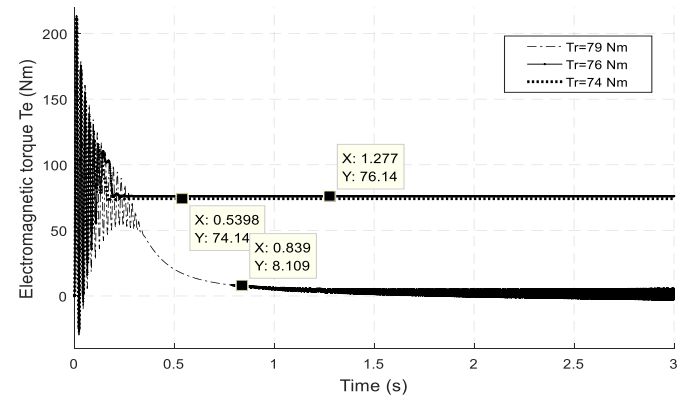

(a) Electromagnetic torque versus time M1

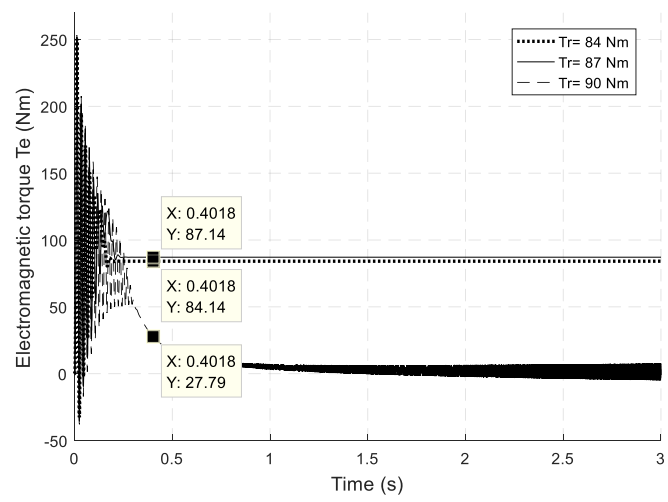

(b) Electromagnetic torque versus time M2

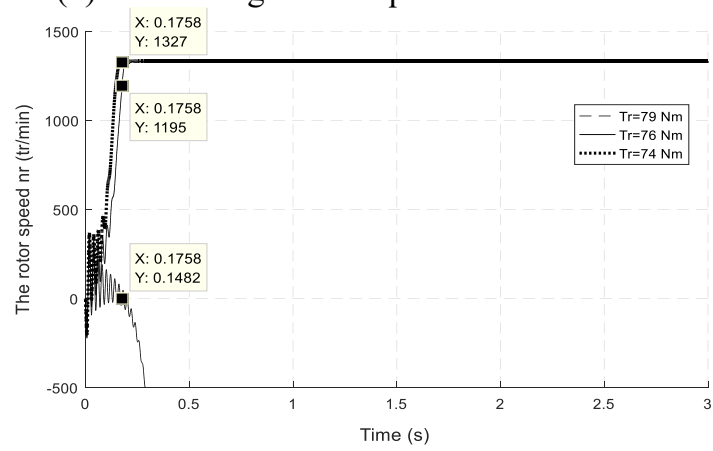

(c) Rotor speed versus time M1

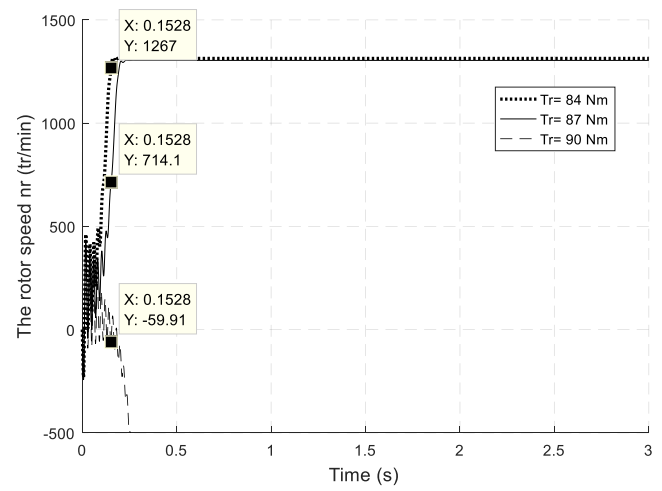

(d) Rotor speed versus time M1

Figure 9. Under starting torque characteristics

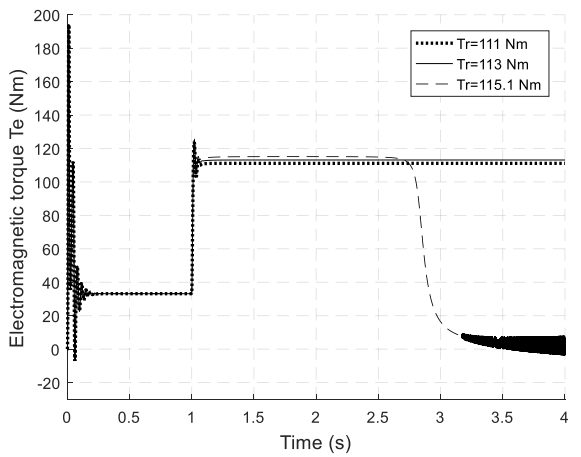

(a) Electromagnetic torque versus time M1

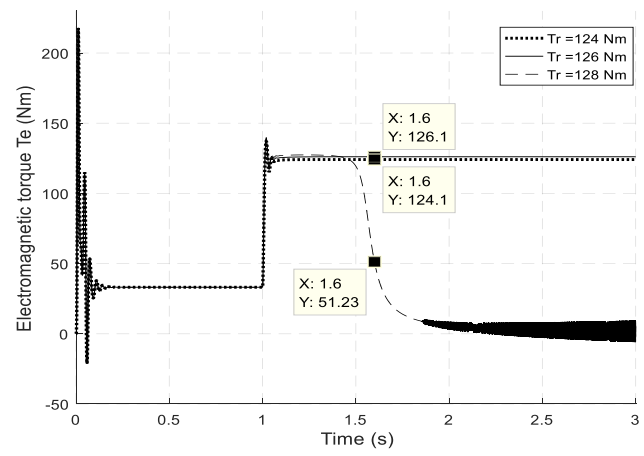

(b) Electromagnetic torque versus time M2

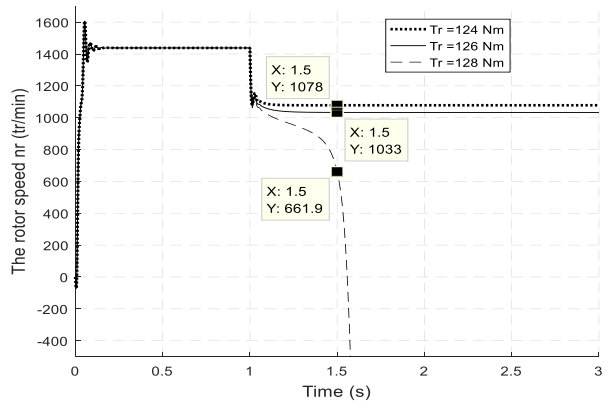

(c) Rotor speed versus time M1

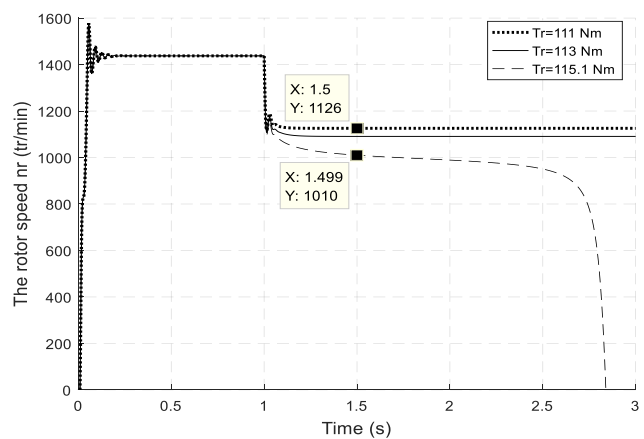

(d) Rotor speed versus time M2

Figure 10. Under maximum torque characteristics

\subsubsection{Results analysis}

According to two machines studied results we note that:

For static results analysis, we are interested to the nominal operating point, which means that when the rotor slip $\mathrm{S}=0.04$, we can see that there is an efficiency improvement for M2 compared to M1.

For dynamic results test, we observe that there is a great improvement in the M2 performance's, they are more remarkable especially in all three tests and can be summarized in the following points: 
(1) M2 response time less than M1, it appears through the developed torque by the two machines and the reach maximum speed time is a smaller amount than M1;

(2) The call current at the start-up and during the walk in charge of M2 is less than M1 and it means that: Warm-ups less; Electrical energy consumption less; Winding long life.

(3) M2 has a better overload capacity.

\subsection{Finite element analyze}

The finite element method (F.E.M), is a numerical method for solving differential equations, with partial derivatives and their boundary condition. This method, was used initially for a structural analysis (mechanics, civil engineering). It was introduced for the first time in electromagnetism by $\mathrm{P}$. Silvester and M.V.K Chari in 1970. Its current scope, covers the following areas:

-Constraints and deformations;

-Fluid mechanics;

-Thermal problems;

-ectromagnetism;

-More recently coupled magneto, thermal and magnetomechanical problems.

In the majority cases, this method integrates with software C.A.O (computer-aided design), which is a great advantage for the engineer called to design the desired physical systems, [4].

The main steps in construction a finite element model are:

-Sub domain discretization;

-Nodal approximation construction by sub domain;

-Elementary matrices calculates problem corresponding to the integral form;

-Elementary matrices Assembly;

-Boundary conditions consideration and equations system resolution.

The supply circuit of our machines is represented by the following figures.

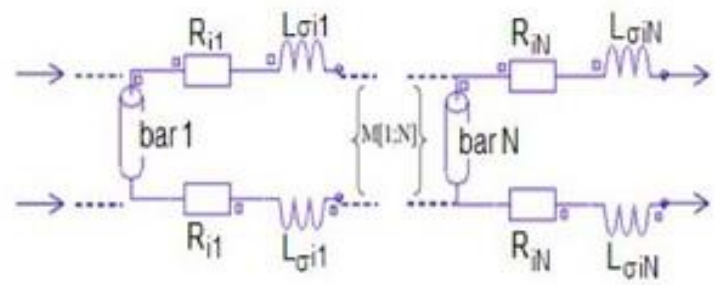

Figure 11. Rotor cage equivalent circuit

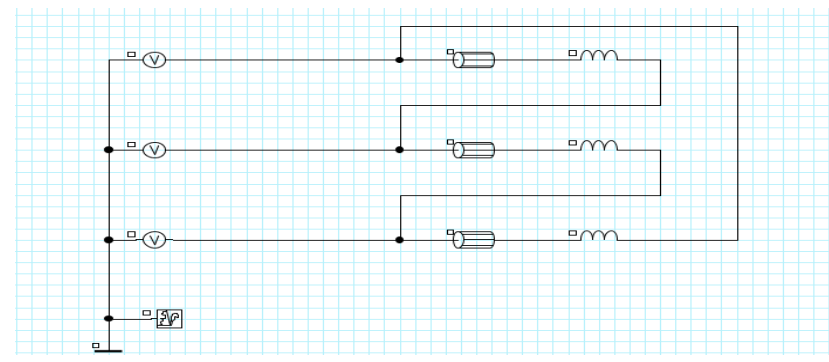

Figure 12. End effects related to geometry circuits

Using the quantities summarized in Table 2, can draw the studied machines geometry whose main results as given in the
Figure 13 and 14. (a) Mesh distribution

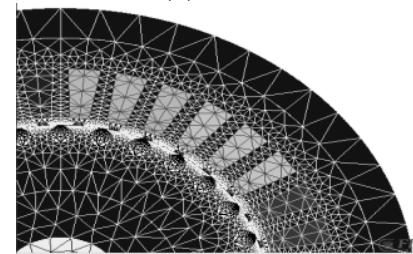

(c) Mesh distribution

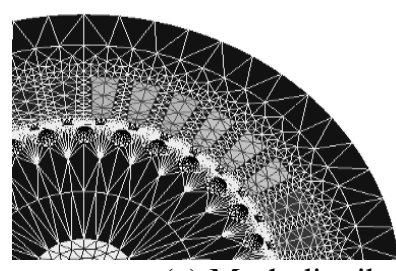

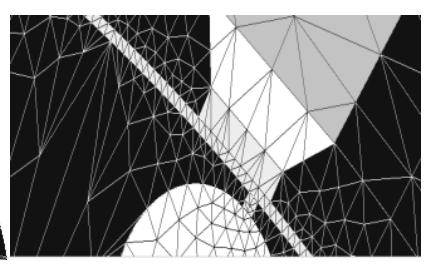

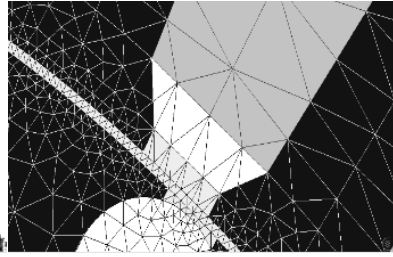

(d) Zoom (b) Zoom

Figure 13. Designed 5kW mesh distributions

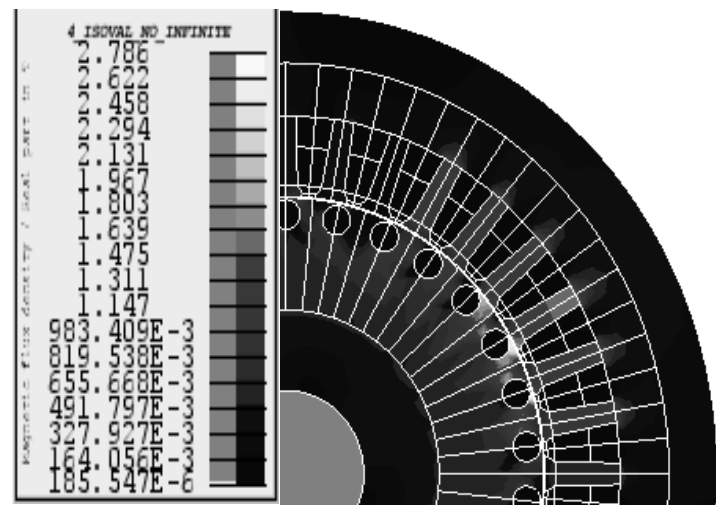

(a) Flux density distribution for M1

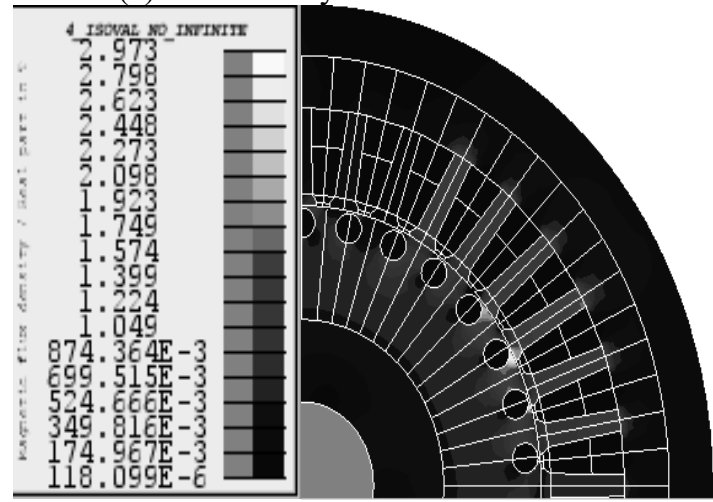

(b) Flux density distribution for M1

Figure 14. Flux density distributions under nominal conditions

In second phase of the design procedure, F.E.M is used to analyze the flux distribution and to check the saturation effects of the machines structure in a nonlinear mag-netostatic model.

Figure 13 and 14 shows the magnetic circuit mesh made for M1 and M2 respectively, we observe that the mesh is denser in the air gap area since the electromagnetic energy develops. On the other hand, is coarser towards the shaft and towards the outside of the cylinder head. Indeed, during our simulation we apply Dirichlet condition with a zero vector potential.

Figure 15 and 16, depict the starting/nominal torque slip response, the current-slip characteristic curve as taken by the developed programs, and show the slots opening effect. 


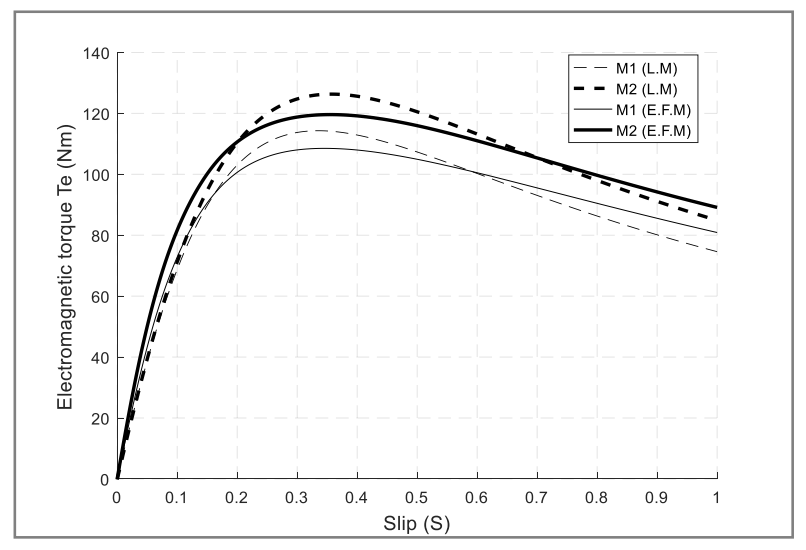

Figure 15. Electromagnetic torque versus rotor slip

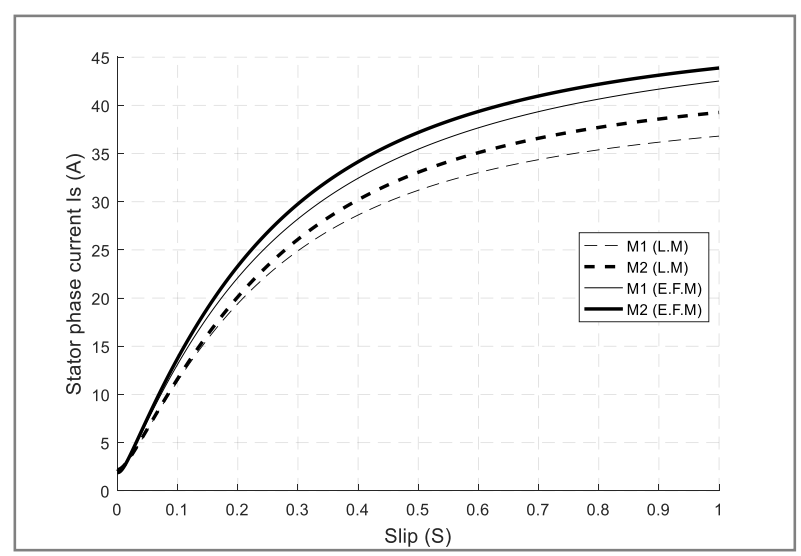

Figure 16. Stator phase current versus rotor slip

\section{CONCLUSION}

This paper has presented and compared design results of two 5-kW conceived motors, obtained from the machine design program developed in our laboratory. Then, in order to validate these conceived motors, a series of simulation and analysis test with SIMULINK under MATLAB environment were performed. These techniques were found very valuable, mainly for costly systems before their implementation. In fact, the numerical results obtained and the simulation analysis performed show that the conceived motor M2 present high performances and capabilities, especially under very hard starting conditions and during overload conditions. It be concluded that opening slot induction motor topology has substantial advantages over the conventional closed rotor slot machine due to the efficiency value by the use of a deep notch stator side. Further to this, these new motors present a relatively better power density ratio, have a robust construction, and are almost free of maintenance, leading to an interesting cost and to a promising solution for on-wheel drive propulsion for example.

\section{REFERENCES}

[1] Chekroun S, Abdelhadi B, Benoudjit A. (2015). A design optimization of induction motor using hybrid genetic algorithm "A Critical Analyze". AMSE Journals, Series Advances C 71(1): 1-23.

[2] Chekroun S, Abdelhadi B, Benoudjit A. (2014). A New approach design optimizer of induction motor using particle swarm algorithm. AMSE Journals, Series Modelling. A 87(2): 89-108.

[3] Verucchi C, Ruschetti R, Kazlauskas G. (2013). High efficiency electric motors: Economic and energy advantages. IEEE Trans. Latin America 11(6): 13251331. https://doi.org/10.1109/TLA.2013.6710379

[4] Zabardast A, Mokhtari H. (2008). Effect of high-efficient electric motors on efficiency improvement and electric energy saving. Third International Conference on Electric Utility Deregulation and Restructuring and Power Technologies: 533-538. https://doi.org/10.1109/DRPT.2008.4523464

[5] Figura R, Szychta E, Szychta L. (2011). In-service efficiency estimation with the use modified air-gap torque method for squirrel-cage induction motor. Electronics and Electrical Engineering Journal 8: 51-56.

[6] 110th Congress of the United States. (2007). The energy independence and security act (EISA) of 2007. An official website of the United States government.

[7] Boglietti A, Cavagnino A, Vaschetto S. (2012). Induction motor EU standards for efficiency evaluation: The scenario after IEC 60034-2-1. IECON 2011 - 37th Annual Conference of the IEEE Industrial Electronics Society, Melbourne, VIC, Australia: 2786-2791.

[8] Saravanan C, Sathiswar J, Raja S. (2015). Y-steadystate performance of induction and transfer field motorsa comparison. Nigerian Journal of Technology (NIJOTECH) 34(2): 385-395.

[9] Calzada-Lara G. (2016). Energetic consumption improvement in induction motors with possible mechatronics applications. Mechanics Based Design of Structures and Machines an International Journal 44(12): $1-23$. https://doi.org/10.1080/15397734.2015.1104511

[10] Sivaraju S, Devarajan N. (2011). Novel design of three phase induction motor enhancing efficiency, maximizing power factor and minimizing losses. European Journal of Scientific Research 58(3): 423-432.

[11] Liwschitz M. (1967). Calcul des machines electriques. Tome 1, Tome 2, Edition Dunod, Paris, France. 